\title{
Blockchain based Trusted Charity Fund-Raising
}

\author{
Ashutosh Ashish Khanolkar, Ashish Rajendra Gokhale, Amrish Sanjay Tembe, Vinayak A. \\ Bharadi
}

\begin{abstract}
The proposed system is a decentralized authentic platform that aims to leverage blockchain along with other technologies to design a trusted framework which would enable charity donations to be as accountable, trustworthy and transparent. The paper explores the potential for deploying blockchain within existing organizations to support smooth conduction of charity funds from the donor to the actual needy person using a stable Ethereum based Blockchain oriented platform. In this fast developing world of modernization, some people are becoming too competitive to earn money while others have no clue about getting even a penny. But at the same time, there exist people who wish to contribute to the society out of altruism. There exist many online donation platforms in the world and yet issues concerning extra fees, accountability and processing delay still exist as well as these existing centralized systems for charities are so corrupt that people lose belief in these trustless systems and hence the charities become futile. This paper explores how the blockchain can be leveraged in the philanthropic sector, through charitable donation services via a web- based donor platform.
\end{abstract}

Keywords: Charity, Blockchain, Cryptocurrency, Ethereum, Ethash

\section{INTRODUCTION}

Charity is a critical part of a democratic society. It is known that there are many incidents take place in this world which causes tragic loss whether it can be related to wealth or life and cause extensive damage every year. To recover from various types of losses many afflicted require help from aid People are now becoming voracious to contribute to the society. So, Charity is a highly growing sector in today's world and it has evolved from its traditional organizational concepts to a decentralized crypto-currency based system. The traditional system globally suffers from various problems

Revised Manuscript Received on July 02, 2020.

* Correspondence Author

Ashutosh Ashish Khanolkar*, Department of Information Technology, Finolex Academy of Management and Technology, Ratnagiri, India. Email: ashutosh.khanolkar@gmail.com

Ashish Rajendra Gokhale, Department of Information Technology, Finolex Academy of Management and Technology, Ratnagiri, India. Email: ashishgokhale32@gmail.com

Amrish Sanjay Tembe, Department of Information Technology, Finolex Academy of Management and Technology, Ratnagiri, India. Email: amrishtembe1998@gmail.com

Dr. Vinayak A. Bharadi, Department of Information Technology, Finolex Academy of Management and Technology, Ratnagiri, India. Email: vinayak.bharadi@famt.ac.in

(C) The Authors. Published by Blue Eyes Intelligence Engineering and Sciences Publication (BEIESP). This is an open access article under the CC BY-NC-ND license (http://creativecommons.org/licenses/by-nc-nd/4.0/) agencies which can be financial aid to basic necessities.

such as lack of transparency, lack of trust between donors and corruption. Blockchain is a remarkably transparent and decentralized way of maintaining this kind of different charity based transactions. So we are going to propose a blockchain based decentralized system that acts as a platform to donate money for donors to other users who have requested for the donation and this entire taking place under maximum security and fulfilled trust.

Fake charities try to take advantage of our generosity and compassion for others in need. Scammers will steal your money by acting as a genuine charity. These scams not only cost you money but they also divert much needed donations away from legitimate charities and causes. Following statistics will state the broader view about this crisis related to frauds in charity [13]:

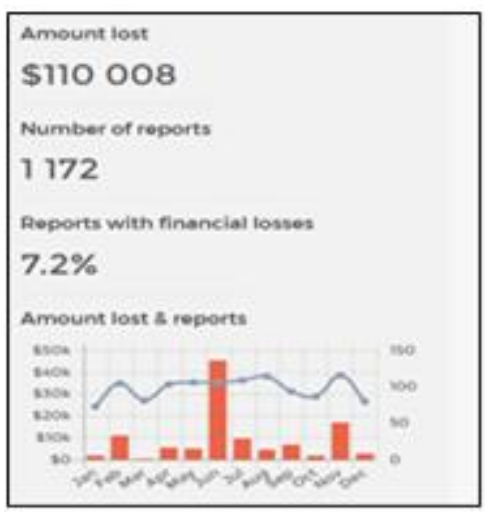

Year 2016

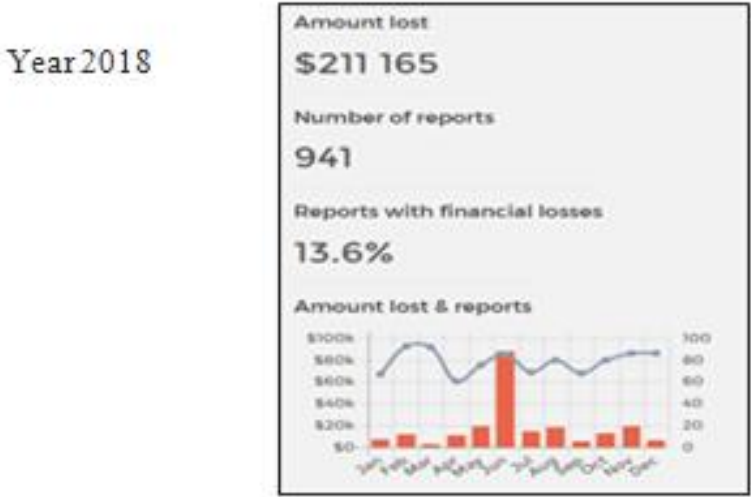

Fig.1. Comparison of statistics of amount lost due to frauds in charity

To overcome these challenges, we are presenting a transparent, secure and trustful platform for the charity fund raising purpose by implementing blockchain which is an open distributed database that monitors cash, merchandise traded or transactions on an open decentralized ledger.

Published By:

Blue Eyes Intelligence Engineering and Sciences Publication

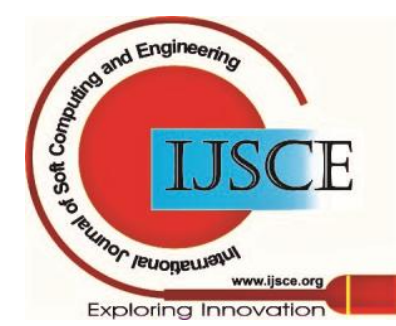




\section{Blockchain based Trusted Charity Fund-Raising}

Fake charity approaches occur all year round and often take the form of a response to real disasters or emergencies, such as floods, storms and earthquakes. Scammers will create their own charity name or pose as either member of well-known popular charities.

In spite of all the transparency that the charitable organizations are trying to incorporate, there still exists the distrust about the way in which this money is being put to practice.

In this proposed paper we present an interesting application of blockchain to build a trusted framework between charity sectors which is organized as follows: Section 1 includes introductory part of the system. In section 2 and 3, existing systems and work related to the topic has been described along with references of literature surveys. Section 4 includes results of the system and section 5 includes performance evaluation and feasibility analysis of the proposed charity fund raising system. While section 6 concludes our research works and future scope with references at the end.

\section{REALATED WORK/LITERATURE SURVEY}

There are many charity fund raising system proposed till date to provide platform for secure and transparent transactions in charity sector. Here, we investigate the existing proposal of the charity fund raising in different fields and identify the research gaps.

Apurv Mehra et.al [2018] have proposed Vishrambh as a platform that aims to leverage blockchain along with other technologies to design a trusted framework which would enable philanthropic donations to be as accountable and transparent as direct charity [8].

Aksel Reiten et.al [2016] has proposed a system which aim to be distributed, verifiable, and transparent, using blockchain technology to meet these specifications. So the system utilizes recent developments in cryptography to design and create a transparent philanthropic microlending platform [1].

Rizal Mohd Nor et.al [2017] has concluded that there exist many online donation platforms in the world and yet issues concerning extra fees, accountability and processing delay still exist. So, he proposed a system which is a decentralized, authentic and transparent donation system to address these issues by implementing Blockchain [9].

Hadi Saleh et.al [2019] has proposed research paper that considers description of implementation of the platform for tracking donations based on blockchain technology. The System offers transparent accounting of operations donors, charitable foundations and recipients based on blockchain technology, charitable platform should provide transparent donation route, enable public users and donors to track and monitor where, when and to whom went resources of charity funds [5].

Ismail Yildirim and Eyyup Ensari Sahin [2018] has proposed research paper to summarize that based on trust, the insurance sector and the use of blockchain may seem contradictory. The research paper suggested that the blockchain technology will bring efficiency and allow for better policy pricing in insurance processes as well as better risk management. It will become an improved insurance compensation experience which will increase the trust factor placed on the sector [10]. Danushka Jayasinghe et.al [2012] ] has proposed research paper to summarize that explores how the blockchain can be leveraged in the philanthropic sector, through charitable donation services in fiat currency or Bitcoin via a web-based donor platform. By using the existing GSM network, an SMS based mobile payment system is proposed for provisioning the received donations [7].

Pratyush Agarwal et,al [2018] has proposed a system which is backed by cryptocurrency transactions, can be made to expand the system of charity being more transparent and trustworthy where the charity (in form of work) by individuals or organizations is done first and then that work can be sold later as a stock [4].

\section{PROPOSED CHARITY FUND RAISING SYSTEM USING BLOCKCHAIN}

\subsection{Objective}

An objective of the proposed Charity Fund Raising System is to provide transparent, secure and trustful platform for charity donations by minimizing the frauds and middle-party interference between the transactions.

Transparency: Accountability is an obligation or willingness by a charity to explain its actions to its stakeholders. Transparency is an obligation by a charity to publish and make available critical data about the organization.

Trust: To establish trust between different phases in the charity organizations like donors and charity organization members.

Authenticity: By validating and authentication of different stakeholders and user increases the transparency and trust in the charity field.

Security: To provide safe and secure charity transactions by minimizing third party frauds and interference is the main objective of this proposed system.

Decentralization: Decentralization of system helps organization to maintain transactions untouched and unchanged by any other member who maintains security and transparency.

\subsection{Background Techniques and Tools}

In the proposed framework, we have implementing blockchain hyperledger consortium for decentralization purpose.

\subsubsection{Ethereum software}

Ethereum which is completely open source is a public blockchain-based distributed computing platform and featuring smart contract functionality. Through its transaction-based state transitions it supports a modified version of consensus by Nakamoto. Ethereum platform generates a Blockchain whose token is Ether.

\subsection{2 web3}

web3.js is a collection of libraries which uses HTTP or IPC connection and make it possible to interact with a local or remote ethereum node.

\subsubsection{AJAX}

Ajax is a set of web development techniques. It is used to create asynchronous web applications by using many web technologies on the client side. By using Ajax, web applications can asynchronously send and retrieve data from a server in the background without interfering behaviour of the existing page.

Published By:

Blue Eyes Intelligence Engineering and Sciences Publication

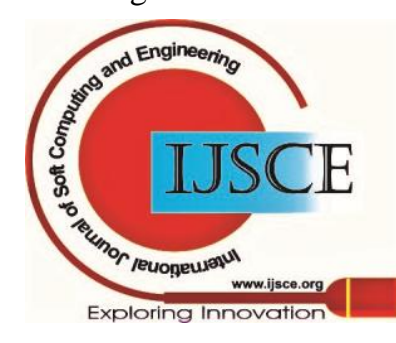




\subsection{Design of the Proposed System}

In the proposed system there are mainly three actors: Donor, Charity Organization and Needy Person. Needy person can request for required amount of funds to the Charity Organizations. Charity Organizations displays all of the fund requests to Donors. Donors can choose the particular cause from respective list and can donate amount. Donor will get the final receipt for his donation which contains all the wallet addresses along with transaction hash. All this transaction process is decentralized and maintained under Blockchain ledger. The charity organization can check the status of events that has been created similarly needy person can also check the status of the events that he/she requested to charity organization.

1. In the proposed system, a donor can make their donation via a Donor Platform.

2. Each charity on the donor platform has a wallet address which is nothing but a public key generated using Elliptic-curve cryptography.

3. Donors can use their dedicated wallet to donate, or use at currency that gets converted to Crypto-Currency.

4. When transaction takes place, the signature will be verified again and if the result is valid then only transaction will be approved and after that transaction will be added to blockchain.

5. Once a donation is made, the donor can query the blockchain to see whether the donated funds have been used or not.

6. The charity then uses the donations to allocate financial aid to individual beneficiaries.

In our proposed system whenever transaction happen between donor and charity it will be send to one of the node which is a 'miner node' on blockchain. Before adding any transaction on the ledger it gets verified. To verify transaction the node solves the problem which is a mining process and transaction has been added to blockchain and it gets its corresponding block number. Ethereum contains the proof of algorithm called Ethhash, It finds out a nonce input to the algorithm. Time needed to find a nonce depends on the threshold. The average time taken by block mining in Ethereum is about 15 seconds. The winning miner will be rewarded with consistent block reward of 5.0 Ether. After this, the blockchain ledger on other nodes will get updated according to the subsequent transactions [12]. Basically, the donors and charity are the clients who basically do the transaction on blockchain so that each transaction will provide transparency between clients.

\section{RESULTS}

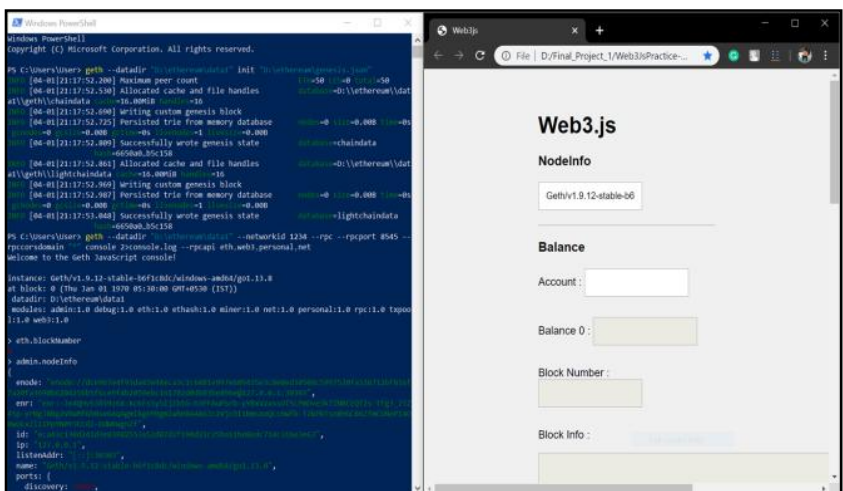

Fig.3.1. Running the geth command to connect to the mainnet network

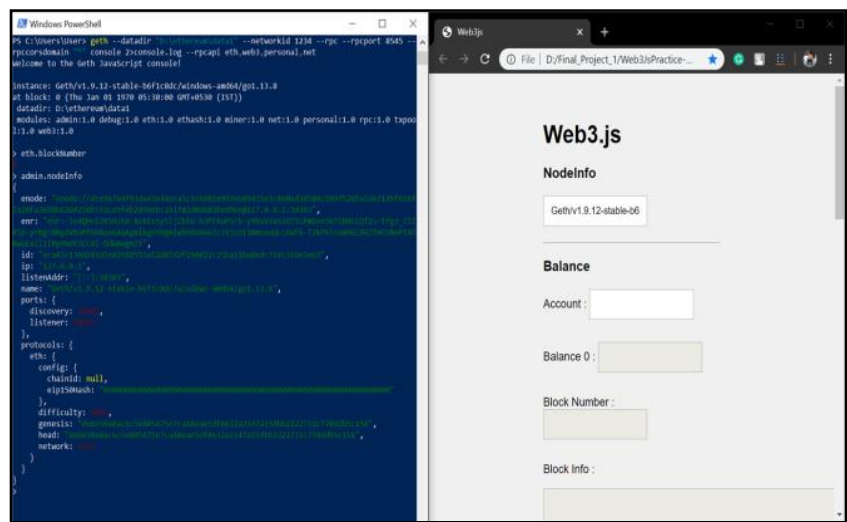

Fig.3.2. The nodeInfo administrative property to know all the information about the running Geth

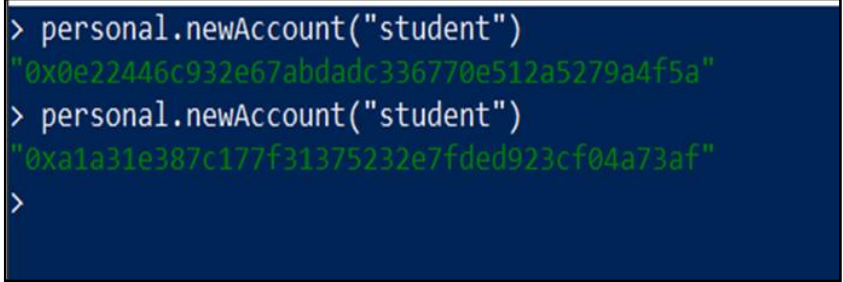

Fig.3.3. Creating new accounts for performing transactions

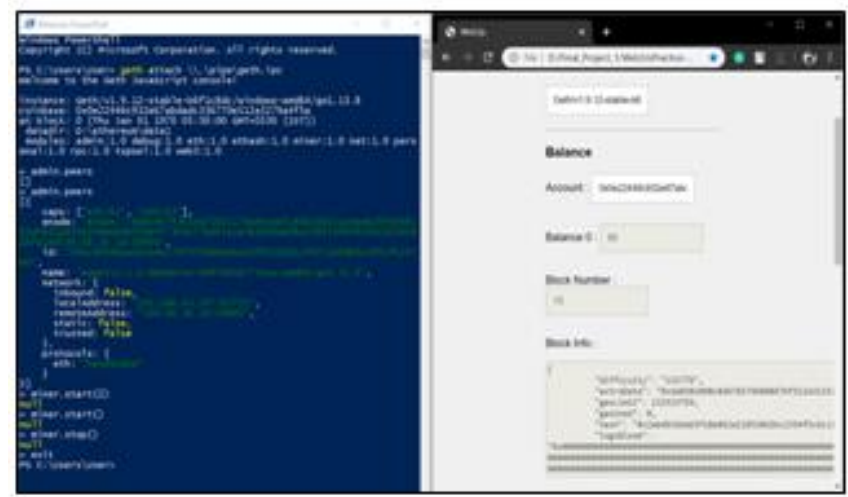

Fig.3.4. Checking connected peers and starting the miner

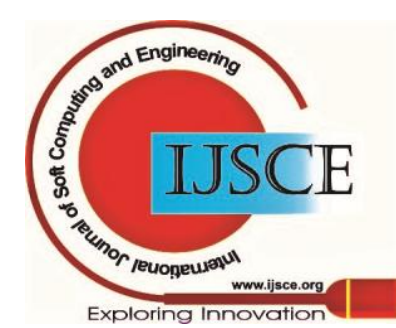




\section{Blockchain based Trusted Charity Fund-Raising}

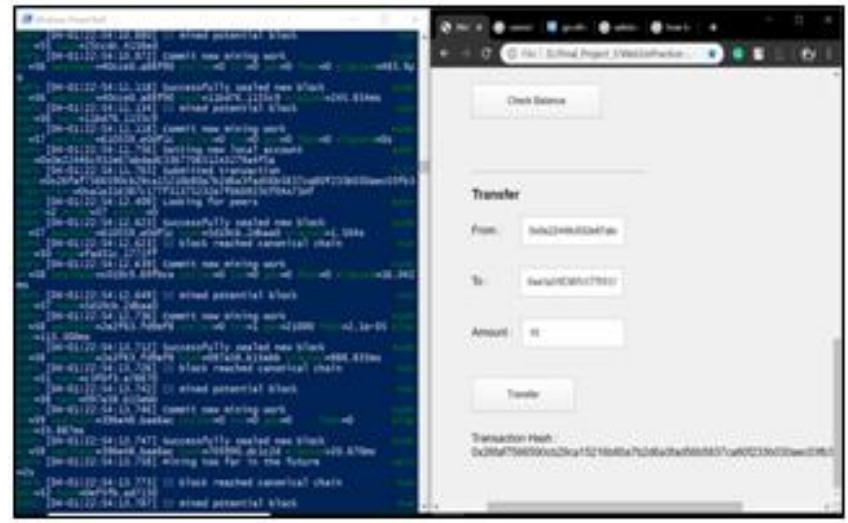

Fig.3.5. Committing and sealing new blocks after starting miner and successful transaction

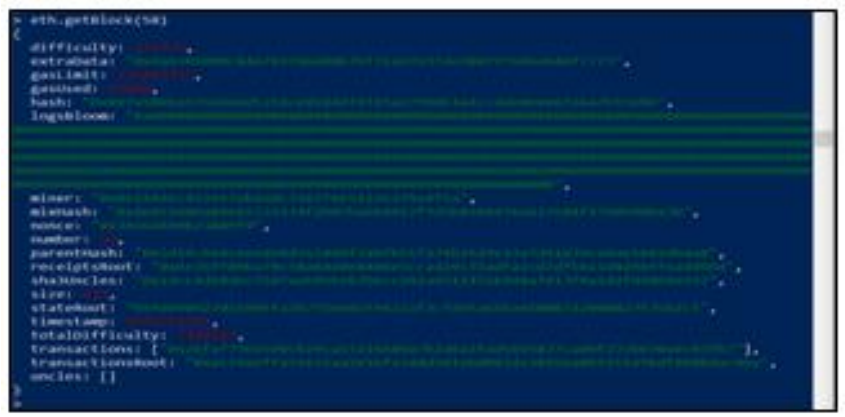

Fig.3.6. Details of random Ethereum Block

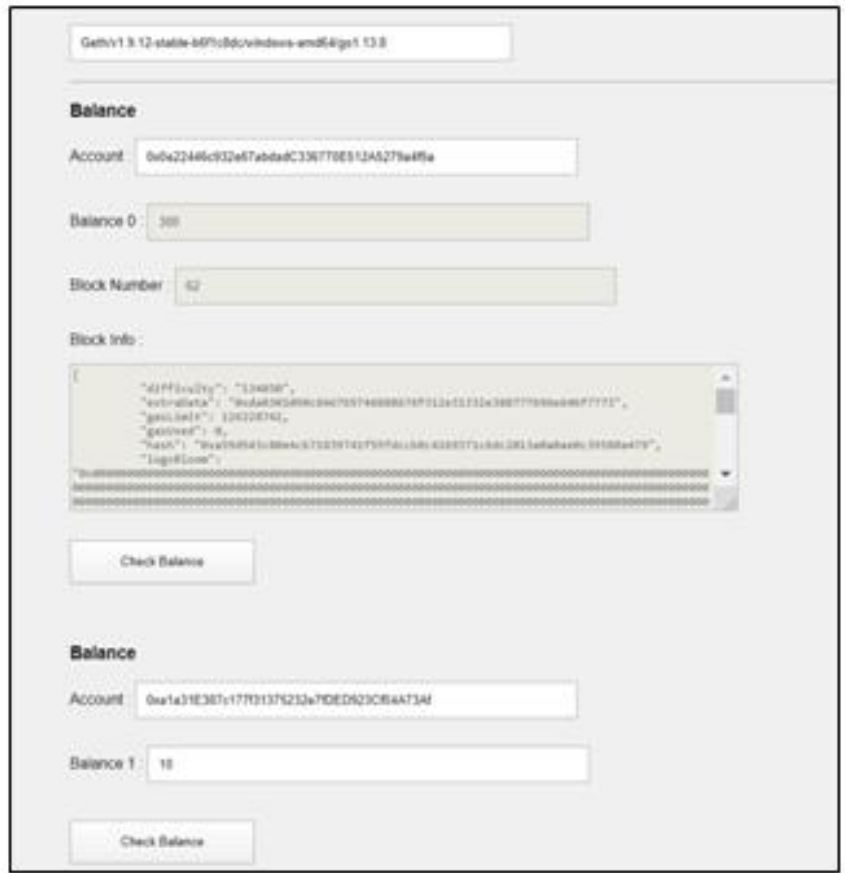

Fig.3.7. Account details by using web3 interface on browser

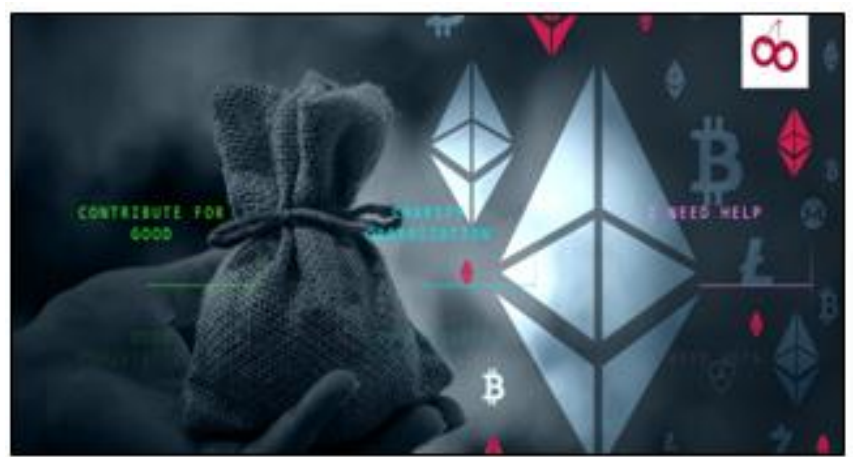

Fig.3.8. GUI for the Home Page

Retrieval Number: A34540710120/2020@BEIESP DOI: 10.35940/ijsce.A3454.0710120

Journal Website: $w$ ww.ijsce.org
Published By:

Blue Eyes Intelligence Engineering and Sciences Publication

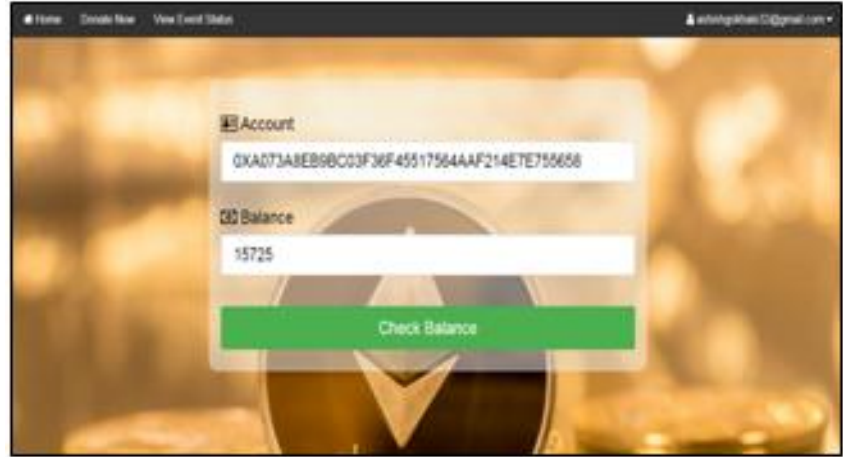

Fig.3.9. GUI for the Ethereum Wallet

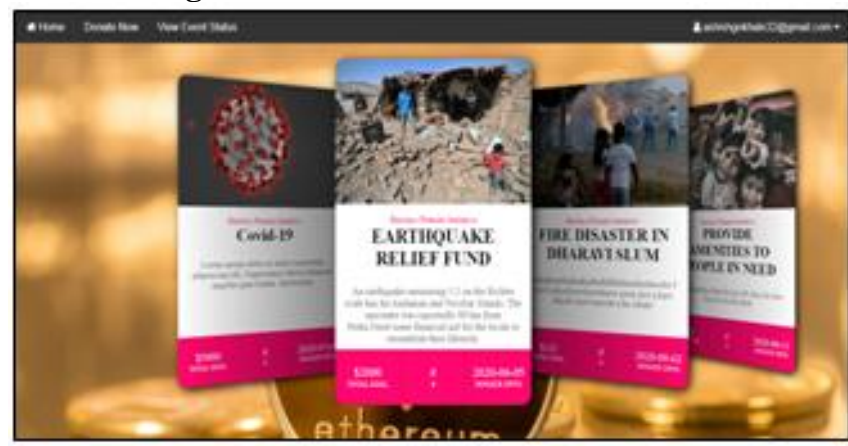

Fig.3.10. GUI of all event lists to view for Donor

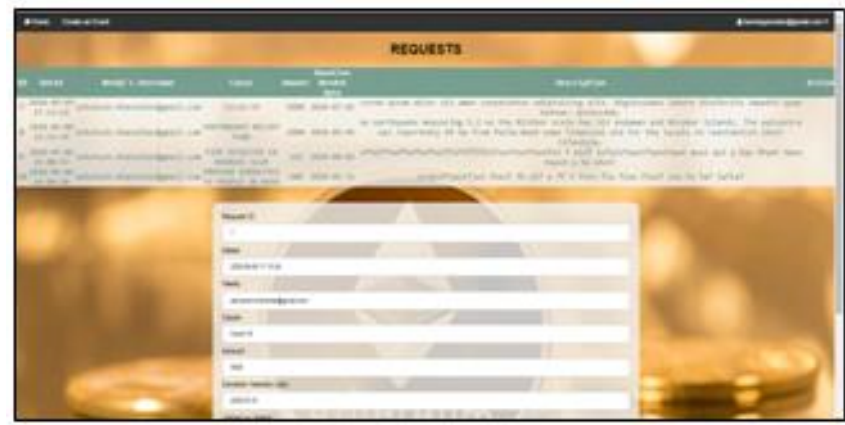

Fig.3.11. GUI for the Charity Organization to create event

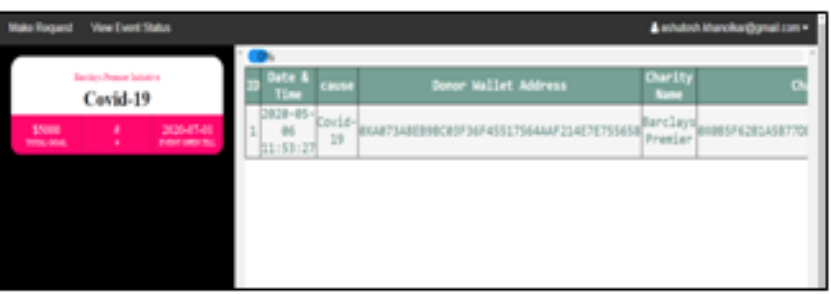

Fig.3.13. GUI for the users to view the status of corresponding events

\section{R EQUIREMENT ANALYSIS}

Scandals have hit confidence within the charity sector. Due to this there is a need of trusted system between the users i.e. Donor and a Charity. Blockchain and cryptocurrency can be one of the solutions to tackle this issue by implementing accountability and transparency. We are proposing a Blockchain based Charity Fund raising system where user demands a trustful and open transactional process. There should be a clear and direct communication between different phase levels in charity like donors, various organizations and actual needy persons.

(C) Copyright: All rights reserved.

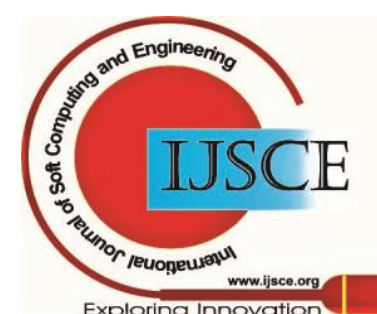


Table- I: Comparison of the proposed framework with the existing works in terms of fulfilling the requirements:

\begin{tabular}{|c|c|c|c|c|c|c|c|c|}
\hline Author & R1 & R2 & R3 & R4 & R5 & R6 & R7 & R8 \\
\hline $\begin{array}{c}\text { Apurv Mehra } \\
\text { et.al [8] }\end{array}$ & $\checkmark$ & $\checkmark$ & $\checkmark$ & $\checkmark$ & $\checkmark$ & $\checkmark$ & $x$ & $\checkmark$ \\
\hline $\begin{array}{c}\text { Aksel } \\
\text { Reiten, et.al } \\
\text { [1] }\end{array}$ & $x$ & $\checkmark$ & $\checkmark$ & $\checkmark$ & $x$ & $x$ & $\checkmark$ & $\checkmark$ \\
\hline $\begin{array}{c}\text { Rizal Mohd } \\
\text { Nor et.al [9] }\end{array}$ & $\checkmark$ & $\checkmark$ & $\checkmark$ & $x$ & $\checkmark$ & $\checkmark$ & $\checkmark$ & $\checkmark$ \\
\hline $\begin{array}{c}\text { Ismail } \\
\text { Yildirim et.al } \\
\text { [10] }\end{array}$ & $\checkmark$ & $\checkmark$ & $\checkmark$ & $\checkmark$ & $x$ & $\checkmark$ & $x$ & $\checkmark$ \\
\hline $\begin{array}{c}\text { Pratyush } \\
\text { Agarwal et,al } \\
\text { [4] }\end{array}$ & $x$ & $\checkmark$ & $\checkmark$ & $\checkmark$ & $\checkmark$ & $x$ & $\checkmark$ & $\checkmark$ \\
\hline $\begin{array}{c}\text { Danushka } \\
\text { Jayasinghe } \\
\text { et,al [7] }\end{array}$ & $\checkmark$ & $x$ & $\checkmark$ & $\checkmark$ & $\checkmark$ & $\checkmark$ & $x$ & $x$ \\
\hline $\begin{array}{c}\text { Proposed } \\
\text { System }\end{array}$ & $\checkmark$ & $\checkmark$ & $\checkmark$ & $\checkmark$ & $\checkmark$ & $\checkmark$ & $\checkmark$ & $\checkmark$ \\
\hline
\end{tabular}

$\checkmark$ Fulfilled, $x$ not fulfilled

R1: The system should be clear about shorter-term outcomes that will contribute to impact, the long-term impact the charity wants to achieve and the and how the charity's work will going to affect these outcomes. Organizations, trustees and those other which are using the charity should understand and work towards the real change theory, which should be published and disseminated.

R2: Giving confidence to people about the factor that the charity understands what it is trying to achieve and how it will do the same. It demonstrates that the charity is regulate with the latest thinking around what works in dealing with the particular social or environmental issue. We can strengthen the mind set of various donors by implementing higher level authenticity and security measures in charity.

R3: The transactional details as well as flow of charity fund through various stages of actors must be transparent to every actor and stakeholders.

R4: System requires experimenting with different methods of consensus algorithms such as proof of stake or proof of importance to achieve faster verifications of transactions.

R5: The main requirement of this system is to build a trustful platform for charity donations by eliminating traditional third party actors responsible for interfering the transactions leading to different frauds by implementing Smart Contracts. R6: From point of view of different stakeholders, by providing complementary services, reducing fragmentation or allowing proven interventions to reach more people, sometimes collaboration within or across sectors, can be the best way to achieve results. Charities should understand how their own actions relate to the work of others and their role within a sector. By looking for collaboration where it is relevant and productive, we can expect charities to have a clear sense of increasing their impact.

R7: Providing a web based platform for blockchain based system to eliminate the limitations caused by hyperledgers.
R8: Users also demand that the charity's fundraising should be cost-effective, sustainable and should align with the charity's mission and values. Trustees need to be comfortable with all the procedures along with agreed policies and confident that they are being followed. This includes meeting the regulatory requirements but also consideration of the moral issues.

By undertaking all of these requirements we tried to achieve a transparent, trustful, open and secure charity fund raising platform from the view of providing immediate help to the actual needy persons or organizations.

\section{CONCLUSION AND FUTURE WORK}

We have proposed a system using Blockchain along with cryptocurrency for charity work to make it more transparent through a decentralized system. Urbanization has made a lot of people more concerned about others and this has made a lot of people altruistic. But at the same time there are also people who want to ultimately make illegal money in the process. This system will provide both the requirements which are better authenticity and security. Also, it will provide with a trusted system and will make the entire process more transparent. This will help get rid of middle men between donors and charity doers.

Because the system does not rely on an intermediary to transfer funds, the speed and cost for handling aid is reduced. The scope of the Blockchain technology is limited due to the unawareness of value of Cryptocurrency. In a scenario where the banking economy can be collapsed, Crypto-Currency will be the only viable option. System can be expanded at global environment. The philanthropic model could be applied in different situations e.g. when smartphones and Internet connectivity are unavailable. The decentralized and democratic structure of especially the open source blockchain platforms prove problematic due to the challenges involved in ensuring these updates are installed at each node. This, in turn, may lead to forking.

\section{REFERENCES}

1. A. Reiten, A. D'Silva, F. Chen and K. Birkeland, "Transparent Philanthropic Microlending", Final Project - 6.857 Network and Computer Security - Spring 2016,Massachusetts Institute of Technology.

2. M. H. Miraz, and M. Ali," Applications of Blockchain Technology beyond Cryptocurrency ", Annals of Emerging Technologies in Computing (AETiC) Vol. 2, No. 1, 2018.

3. R. Bunduchi, K. Symons, and C. Elsden," Adding value with blockchain: an explorative study in the charity retail sector",June 2018.

4. P. Agarwal, S. Jalan, A. Mustafi," Decentralized and financial approach to effective charity ",2018 International Conference on Soft-computing and Network Security (ICSNS).

5. Hadi Saleh, Sergey Avdoshin, Azamat Dzhonov," Platform for Tracking Donations of Charitable Foundations based on Blockchain Technology" Actual Problems of Systems and Software Engineering (APSSE), 2019.

6. S. T. Aras, V. Kulkarni," Blockchain and Its Applications - A Detailed Survey ", International Journal of Computer Applications (0975 - 8887) Volume 180 - No.3, December 2017.

7. D. Jayasinghe, S. Cobourne, K. Markantonakis, R. N. Akram and K. Mayes," Philanthropy On The Blockchain", 2012.

Published By:

Blue Eyes Intelligence Engineering and Sciences Publication

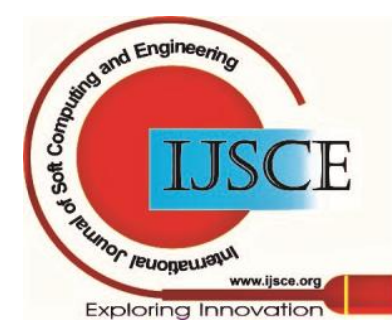




\section{Blockchain based Trusted Charity Fund-Raising}

8. A. Mehra, A. Jain, S. Singanamalla, S. Lokam, M. Sivathanu, J. O’Neill, "Vishrambh: Trusted Philanthropy with end-to-end Transparency ", 2018.

9. R. M. Nor, M.M H. Rahman, T. Rahman and A. Abdullah," Blockchain Sadaqa Mechanism For Disaster Aid Crowd Funding ", Proceedings of the 6th International Conference on Computing and Informatics, ICOCI 2017.

10. I. Yildirim and E. E. Sahin, "Insurance Technologies (Insurtech): Blockchain And Its Possible Impact On Turkish Insurance Sector ", Journal of International Management, Educational and Economics Perspectives 6 (3) (2018) 13-22.

11. G. M. A. Junior, J. N. D’Almeida., M. T. Onodera, S. M. B. M. Moreno, V. R. S. Almeida BNDES ,"Improving the Process of Lending, Monitoring and Evaluating through Blockchain Technologies",2018 IEEE Confs on Internet of Things, Green Computing and Communications, Cyber, Physical and Social Computing, Smart Data, Blockchain, Computer and Information Technology, Congress on Cybermatics.

12. Sajana P., Sindhu M., M. Sethumadhavan, "On Blockchain Applications: Hyperledger Fabric and Ethereum", International Journal of Pure and Applied Mathematics, Volume 118 No. 18 2018, 2965-2970.

13. https://www.scamwatch.gov.au/types-of-scams/fake-charities.

\section{AUTHORS PROFILE}

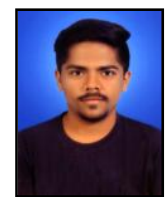

Mr. Ashutosh Ashish Khanolkar pursuing his bachelors of Engineering in Information Technology branch from Finolex Academy of Management and Technology, Ratnagiri, Maharashtra. His area of interest includes Blockchain technology related work and web designing. He also has good coding skills in java, javascript and web development technologies.

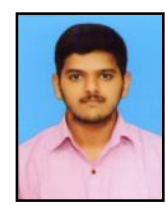

C\#.

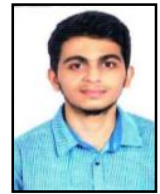

Mr. Amrish Sanjay Tembe pursuing his bachelors of Engineering in Information Technology branch from Finolex Academy of Management and Technology, Ratnagiri, Maharashtra. His area of interest includes Blockchain technology related work and data mining. He also has good coding skills in java, $\mathrm{C}$ and $\mathrm{C}++$.

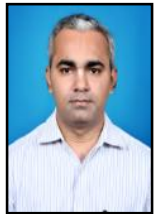

Dr. Vinayak A. Bharadi is a Head of Information Technology Department and Associate Professor at Finolex Academy of Management and Technology, Ratnagiri, Maharashtra. He is having Doctor of Philosophy (Ph.D.) in Computer Engineering. He completed B.E. in Electronics Engineering and M.E. in Electronics and Telecommunication Engineering. His area of interest includes research and development in technology.

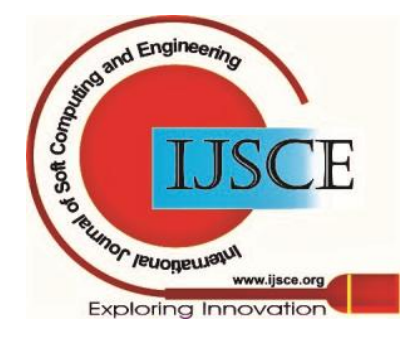

